\title{
Structure and Mechanical Properties of the Welded Joints of Large-Diameter Pipes
}

\author{
V. A. Khotinov ${ }^{a}$, A. B. Arabei ${ }^{b}$, I. Yu. Pyshmintsev ${ }^{c}$, and V. M. Farber ${ }^{a}$ \\ ${ }^{a}$ Ural Federal University, ul. Mira 51, Yekaterinburg, Russia \\ e-mail: khotinov@yandex.ru \\ ${ }^{b}$ Gazprom, Moscow, Russia \\ ${ }^{c}$ Russian Research Institute for Pipe Industry, ul. Novorossiiskaya 30, Chelyabinsk, 454139 Russia \\ Received April 5, 2011
}

\begin{abstract}
The structure and mechanical properties of the technological welded joints of large-diameter pipes of strength class K60 produced by two companies are studied. Along with standard mechanical properties $\left(\sigma_{0.2}, \sigma_{\mathrm{u}}, \delta, \psi\right)$, specific work of deformation $a$ (tensile toughness) and true rupture strength $S_{\mathrm{f}}$ are estimated from an analysis of the stress-strain diagrams constructed in true coordinates. The mechanical behavior is found to be different for samples cut from different zones of a welded joint (central weld, heat-affected zone, and base metal). The mutual correlation between parameters $a, S_{\mathrm{f}}$, and impact toughness $K C \mathrm{~V}$ is considered.
\end{abstract}

DOI: $10.1134 / \mathrm{S} 003602951305008 \mathrm{X}$

\section{INTRODUCTION}

The efficiency of applying high-strength low-carbon microalloyed steels as the materials of welded pipes for high-pressure main pipelines is provided by a set of the operating characteristics of a metal, in particular, a combination of a high strength, plasticity, and fracture toughness $[1,2]$. The strength properties of the weldedjoint material determine the reliability of operating main pipelines, and the aim of all manufacturers of welded pipes is to make the structures and mechanical properties of the welded-joint material and the base tube material maximally close to each other. Because of the existing differences in the welding materials and equipment, each company reaches this aim using specific technological approaches.

The technology of manufacturing welded pipes to $1420 \mathrm{~mm}$ in diameter includes a multipass multirow (usually, four-row) arc welding of strips under flux $[3,4]$. Because of the multilayer formation of a weld during repeated thermal cycles of heating of the preceding metal layers, a number of regions (weld center zone (WCZ), weld root (WR), heat-affected zone (HAZ)) with different structural states and levels of mechanical properties can be separated. The technical requirements imposed on the next-generation pipes and welded joints exclude their brittle fracture; in this connection, it is important to study the structure and mechanical properties of a weld as a potential source of a low fracture toughness of a metal.

The aim of this work is to study the structure and mechanical properties of the welded joints of largediameter pipes belonging to strength class K60.

\section{EXPERIMENTAL}

We studied the welded joints of pipes of strength class K60 (Kh70) $1420 \mathrm{~mm}$ in diameter and $25.8 \mathrm{~mm}$ in wall thickness produced by companies A and B. The metal structure was studied in all weld zones (Fig. 1). The specimens for mechanical tests were cut from $\mathrm{CW}$, HAZ, and base metal (BM) (Fig. 2). The chemical composition of the BM is given in Table 1.

Because the individual zones, especially HAZ, have small widths, the specimens cut from them contain comparatively small amounts of the metals of the neighboring zones. This fact, as shown in what follows, did not prevent us from obtaining a correct level of the mechanical properties of each zone and section.

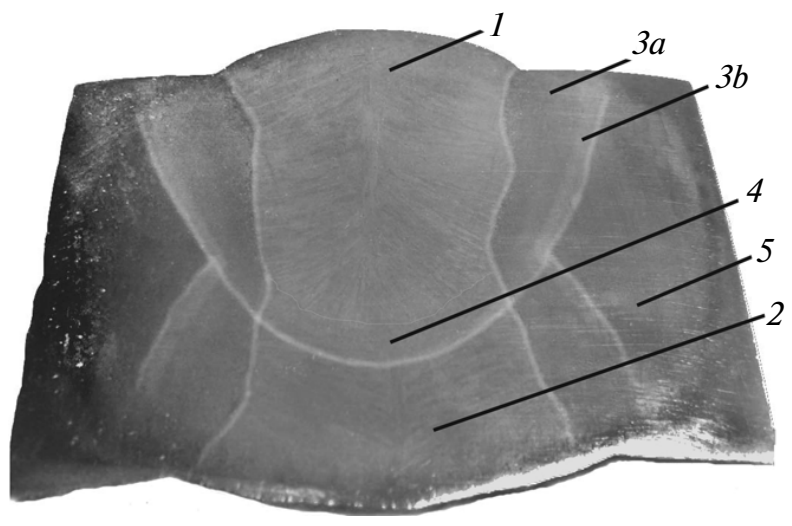

Fig. 1. Macrostructure of a pipe welded joint: (1) CW; (2) RW; $(3 a)$ and $(3 b)$ coarse-grained HAZ $\left(\mathrm{HAZ}_{\mathrm{cg}}\right)$ and fine-grained $\mathrm{HAZ}\left(\mathrm{HAZ}_{\mathrm{fg}}\right)$, respectively; (4) zone of recrystallization of the RW metal under action of the melting temperature of $\mathrm{CW}$; and (5) base metal (BM). 
Bending impact tests were performed on a MK-30 pendulum impact testing machine using Charpy specimens at temperatures of $0,-20,-40,-60$, and $-80^{\circ} \mathrm{C}$. More than three specimens were studied at each temperature.

The tensile tests of fivefold cylindrical specimens $10 \mathrm{~mm}$ in diameter were performed on an Instron 3382 universal testing machine at a rate of $0.7 \times 10^{-3} \mathrm{~s}^{-1}$ at room temperature.

The most usual mechanical behavior of metallic materials during deformation is a decrease in the hardening rate with increasing strain $[5,6]$. In this case, the true stress $S$-relative reduction of area $\psi$ curve is described by the power law

$$
S=K \psi^{n},
$$

where $K$ is the strain-hardening coefficient (MPa) and $n$ is the strain-hardening exponent (Fig. 3). Analyzing the stress-strain curve, we found work of deformation $A(\mathrm{~J})$ as the area under the curve,

$$
A=\int S d \psi \text {. }
$$

Then, the power law of the strain hardening is expressed as

$$
A=K \psi^{n+1} /(n+1) .
$$

The specific work of deformation (tensile toughness) $a\left(\mathrm{~J} / \mathrm{mm}^{3}\right)$ was found as the work corresponding to a certain stage of plastic deformation $\left(A_{\mathrm{u}}\right.$ and $A_{\mathrm{c}}$ for uniform and concentrated plastic deformation, respectively) related to volume $V_{0}$ of the gage portion of the specimen,

$$
a=A / V_{0}=A / F_{0} l_{0},
$$

where $F_{0}$ is the initial area of the specimen cross section and $l_{0}$ is the initial calculation specimen length.

True rupture strength $S_{\mathrm{f}}$ was found as the ratio of load $P_{\mathrm{f}}$ to cross-sectional area of the specimen $F_{\mathrm{f}}$ at the fracture time,

$$
S_{\mathrm{f}}=P_{\mathrm{f}} / F_{\mathrm{f}},
$$

and relative reduction of area $\psi_{\mathrm{f}}$ was found from the relationship

$$
\psi_{\mathrm{f}}=\ln \left(F_{0} / F_{\mathrm{f}}\right) .
$$

\section{RESULTS AND DISCUSSION}

The microstructure of the $\mathrm{BM}$ of the pipes under study is an ultradispersed (the structural component

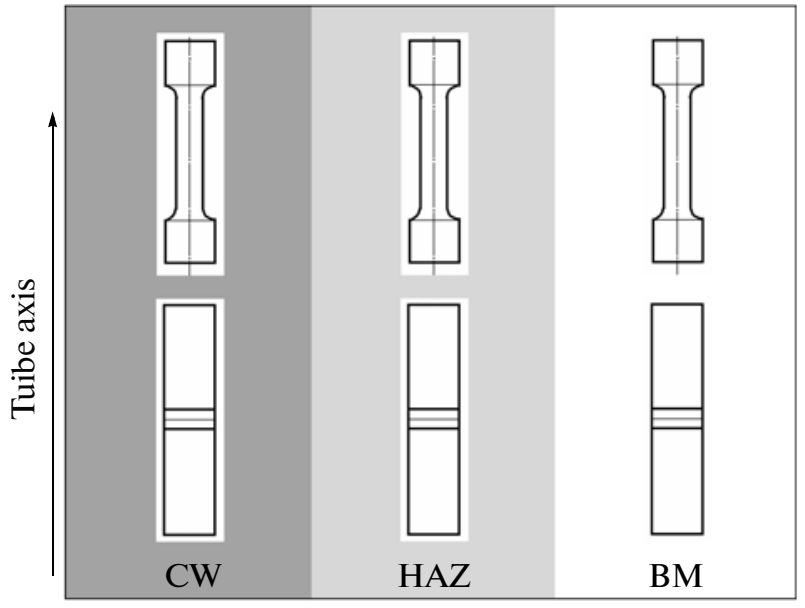

Fig. 2. Scheme of cutting specimens for mechanical tests.

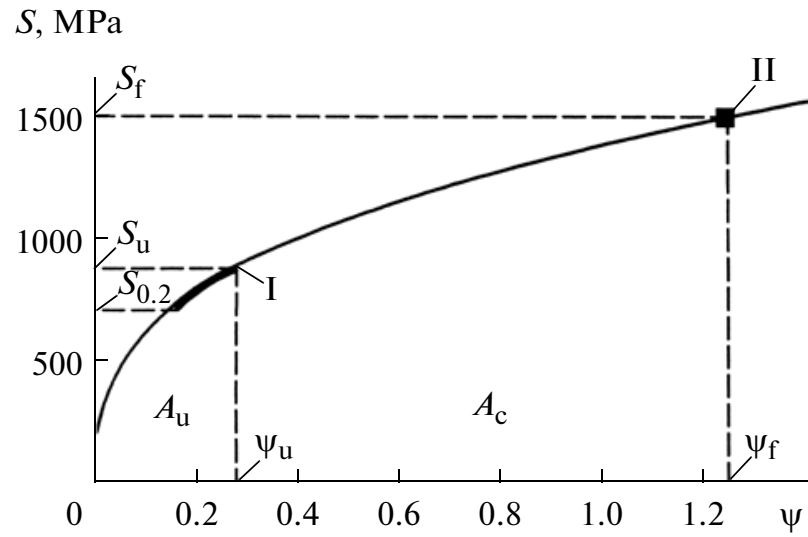

Fig. 3. Stress-strain diagram in true coordinates: (I) necking $\left(S_{\mathrm{u}}\right.$ and $\psi_{\mathrm{u}}$ are the stress and relative reduction of area for the stage of uniform deformation), (II) final fracture $\left(S=1379 \psi^{0.357}, R^{2}=0.970\right)$.

size is $\leq 10 \mu \mathrm{m}$ ) mixture of ferrite and the low-temperature decomposition products of supercooled austenite (bainite and/or martensite) in a ratio of $\sim 70 / 30$ (Fig. 4a).

During welding, the pipe base metal is heated to a temperature higher than $1000^{\circ} \mathrm{C}$; as a result, austenite grains grow and carbides dissolve in HAZ. This increases the stability of supercooled austenite, which leads to the formation of needlelike structural components upon subsequent rapid cooling $\left(20-30^{\circ} \mathrm{C} / \mathrm{s}\right)$ and, therefore, to the embrittlement of the HAZ material.

Table 1. Chemical composition (wt \%) of BM of pipes A (numerator) and B (denominator)

\begin{tabular}{c|c|c|c|c|c|c|c|c|c}
\hline $\mathrm{C}$ & $\mathrm{Mn}$ & $\mathrm{Si}$ & $\mathrm{V}$ & $\mathrm{Nb}$ & $\mathrm{Ti}$ & $\mathrm{Cr}$ & $\mathrm{Mo}$ & $\mathrm{B}$ & $\mathrm{Cu}$ \\
\hline$\frac{0.06}{0.05}$ & $\frac{1.69}{1.87}$ & $\frac{0.20}{0.10}$ & $\frac{0.04}{-}$ & $\frac{0.07}{0.02}$ & $\frac{0.017}{0.019}$ & $\frac{0.03}{0.26}$ & $\frac{0.21}{0.01}$ & $\frac{-}{0.0001}$ & $\frac{0.06}{0.49}$ \\
\hline
\end{tabular}



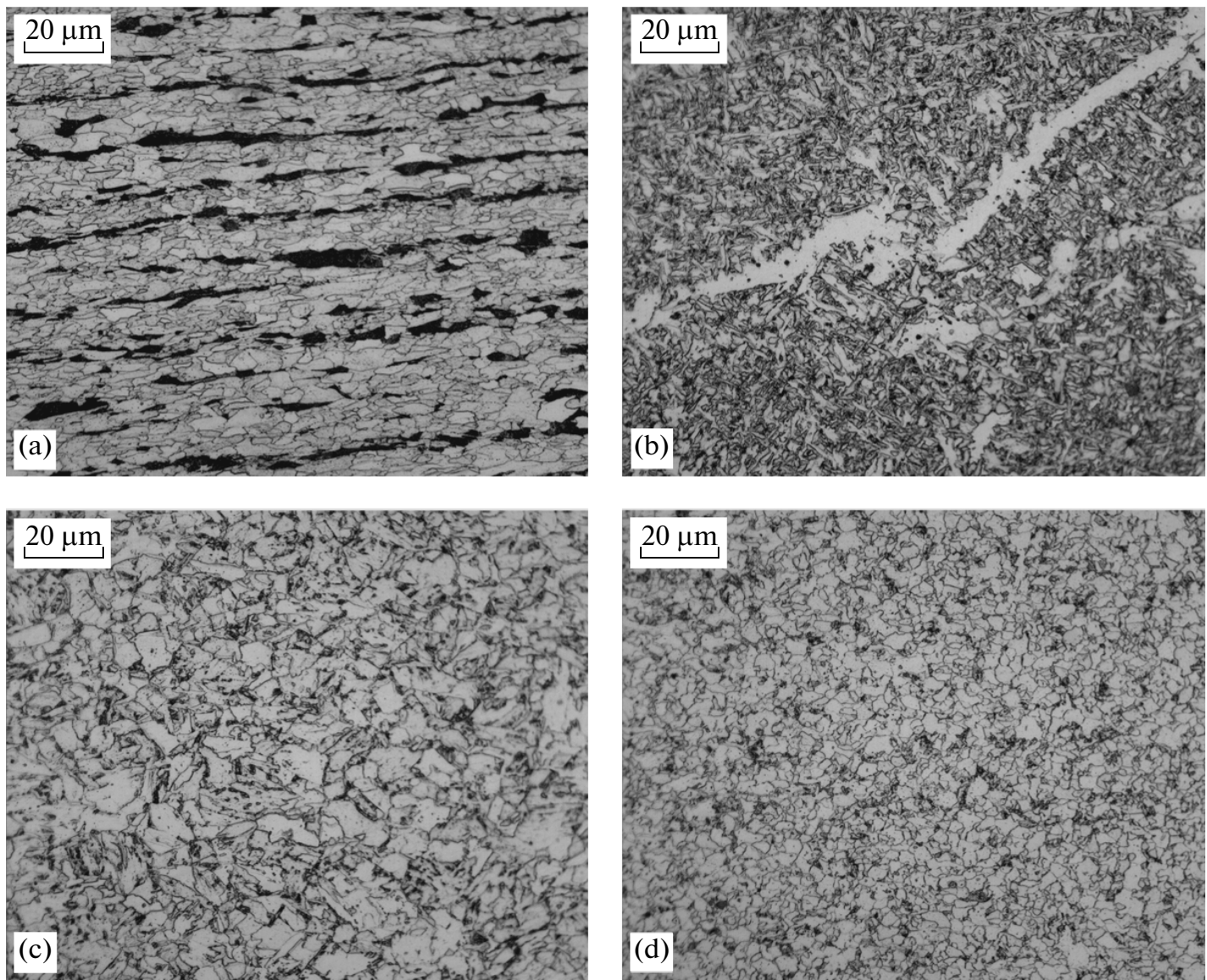

Fig. 4. Microstructure of the welded joint of pipe of manufacturer $A$ in (a) $B M$, (b) CW, (c) $H A Z_{c g}$, and (d) $H A Z_{f g}$.

The CZ metal structure consists of various-size dendrites, from which the coarsest (to $\sim 70 \mu \mathrm{m}$ ) ferrite dendrites form predominantly in primary arms and more disperse dendrites also contain bainite and/or martensite (Fig. $4 \mathrm{~b})$. The coarse-grained $\mathrm{HAZ}_{\mathrm{cg}}$ adjacent to the central weld contains 10 - to $20-\mu \mathrm{m}$ ferrite grains and the low-temperature products of the decomposition of supercooled austenite (Fig. 4c).

The structure dispersion in the fine-grained heataffected zone $\mathrm{HAZ}_{\mathrm{fg}}$ following $\mathrm{HAZ}_{\mathrm{cg}}$ increases: the grain sizes are 5-10 $\mu \mathrm{m}$, and the crystals of hardening phases (bainite and/or martensite) are refined and distributed over the volume more uniformly (Fig. 4d).

Figure 5 depicts the results of mechanical tests as primary stress-strain diagrams. The specific feature of the pipe specimens under study after their operating for about two years is the formation of a yield plateau and a yield drop in the diagram. It is known $[5,7]$ that the formation, level, and value of a yield drop and a yield plateau in steels are determined by the volume fraction and grain size of ferrite and the density of ferrite lattice defects pinned in it by interstitial atom atmospheres.

The stress-strain curve for the specimens cut from the pipe central weld of manufacturer A (pipe A) has a yield plateau, which is absent in the curves for the spec- imens of HAZ and BM. A welded joint on the pipe of manufacturer B (pipe B) demonstrated different behavior of the metal in the zones under study: the stressstrain curve of the central weld metal has a yield plateau along with a yield drop, and the curves for HAZ and $\mathrm{BM}$ only have a yield plateau.

According to these data, the density of lattice defects pinned by atomic atmospheres and/or disperse particles is maximal in the weld metal of pipe $\mathrm{B}$, and this fact negatively influences the level of viscoplastic characteristics in this region and increases the yield strength (Fig. 6).

Pipes A have comparatively low values of $\sigma_{0.2}, \sigma_{\mathrm{u}}$, and ratio $\sigma_{0.2} / \sigma_{\mathrm{u}} \approx 0.75$ in BM in HAZ, which provide very high impact toughness $K C \mathrm{~V}^{-20}=300 \mathrm{~J} / \mathrm{cm}^{2}$ up to a test temperature $T_{\text {test }}=-80^{\circ} \mathrm{C}$.

These data and completely ductile type of fracture show that the ductile-brittle transition temperature of the metal in these regions is lower than $-80^{\circ} \mathrm{C}$. The strength properties of the central weld metal are highest $\left(\sigma_{0.2} / \sigma_{\mathrm{u}} \approx 0.90\right)$ and, hence, the toughness characteristics are lowest (Fig. 6). The completely ductile fracture of the specimens cut from CWZ at $T_{\text {test }}>-40^{\circ} \mathrm{C}$ with an acceptable level of $K C \mathrm{~V} \approx 150 \mathrm{~J} / \mathrm{cm}^{2}$ is changed by 

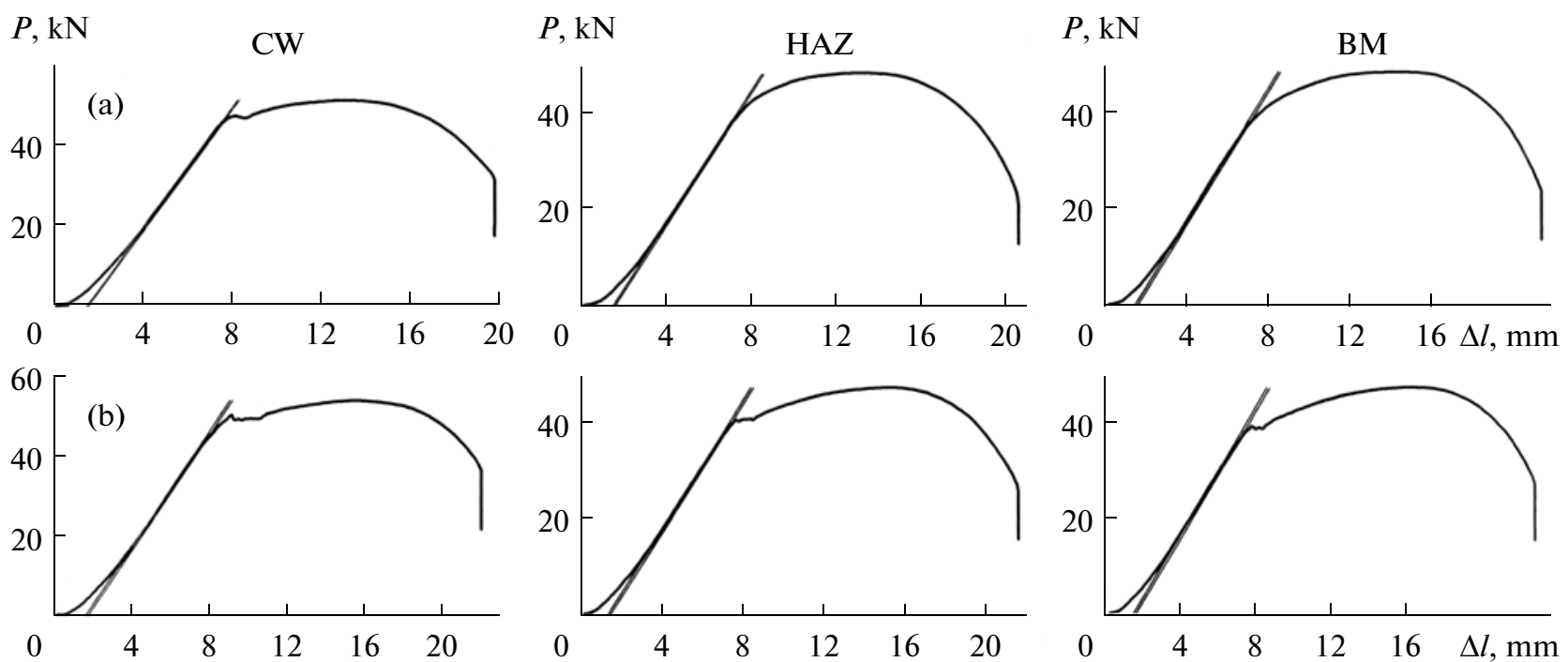

Fig. 5. Primary stress-strain diagrams of specimens ((a), (b) for pipes of manufacturers A and B, respectively) cut from various zones of pipes with welded joints.
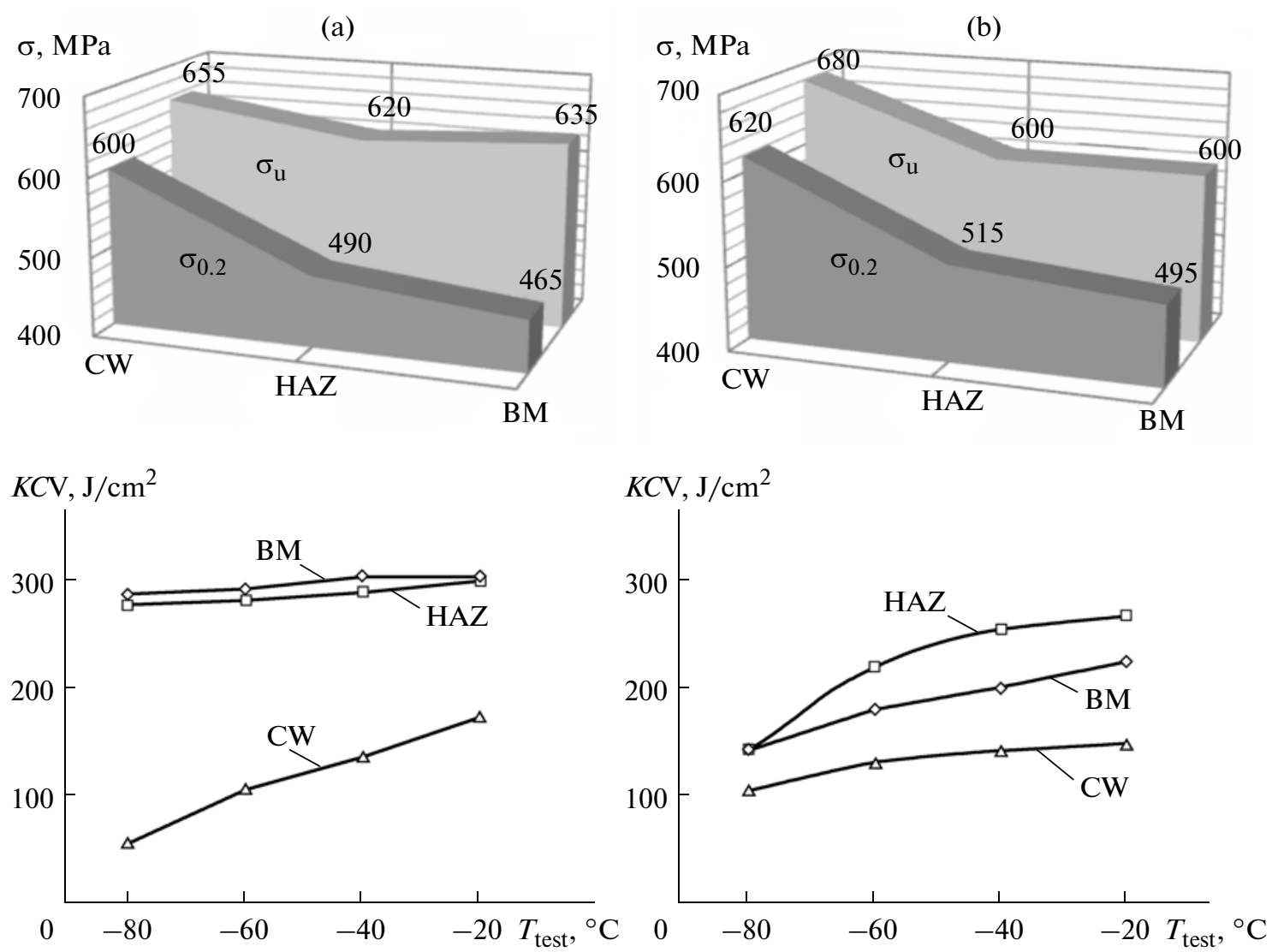

Fig. 6. Mechanical properties of specimens ((a), (b) for pipes of manufacturers A and B, respectively) cut from various zones of a welded joint. 
Table 2. Mechanical characteristics of the metal in the zones of welded joints found from stress-strain diagrams in true coordinates

\begin{tabular}{|c|c|c|c|c|c|c|c|c|c|}
\hline \multirow{2}{*}{ Specimen } & $S_{0.2}$ & $S_{\mathrm{u}}$ & \multirow{2}{*}{$S_{\mathrm{u}} / S_{0.2}$} & \multirow{2}{*}{$e_{\mathrm{u}}$} & \multirow{2}{*}{$S_{\mathrm{f}}, \mathrm{MPa}$} & \multirow{2}{*}{$S_{\mathrm{f}} / S_{\mathrm{u}}$} & \multirow{2}{*}{$\psi_{\mathrm{f}}$} & \multirow{2}{*}{$\mathrm{K}$} & \multirow{2}{*}{$n$} \\
\hline & \multicolumn{2}{|c|}{$\mathrm{MPa}$} & & & & & & & \\
\hline \multicolumn{10}{|c|}{ Manufacturer A } \\
\hline $\mathrm{CW}$ & 600 & 717 & 1.20 & 0.10 & 1490 & 2.08 & 1.24 & 1379 & 0.36 \\
\hline HAZ & 490 & 675 & 1.38 & 0.09 & 2090 & 3.10 & 1.70 & 1601 & 0.46 \\
\hline $\mathrm{BM}$ & 465 & 710 & 1.53 & 0.11 & 1980 & 2.80 & 1.59 & 1665 & 0.50 \\
\hline \multicolumn{10}{|c|}{ Manufacturer B } \\
\hline $\mathrm{CW}$ & 620 & 767 & 1.24 & 0.12 & 1355 & 1.77 & 1.09 & 1325 & 0.39 \\
\hline HAZ & 515 & 677 & 1.31 & 0.12 & 1515 & 2.24 & 1.36 & 1450 & 0.39 \\
\hline BM & 495 & 685 & 1.38 & 0.13 & 1465 & 2.14 & 1.33 & 1473 & 0.47 \\
\hline
\end{tabular}

the formation of a brittle component in fracture at $T_{\text {test }} \leq-60^{\circ} \mathrm{C}$.

As compared to this, the pipe $\mathrm{B}$ weld region demonstrates a better serial curve and completely ductile fracture up to $T_{\text {test }}=-60^{\circ} \mathrm{C}$. The specimens cut from BM and HAZ exhibit higher strengths and lower viscoplastic characteristics (but higher than those allowable according to the normative requirements) than those of similar specimens from pipe A.

An analysis of the stress-strain diagrams in the true coordinates allows the elucidation of the peculiarities of strain hardening of the metal from various zones of pipe weld joints of both manufacturers (Table 2). It is seen that true yield strength $S_{0.2}$ is a characteristic more sensitive to changes in the structure than true ultimate strength $S_{\mathrm{u}}: S_{0.2}$ decreases from $600 \mathrm{MPa}$ in CWZ to $465 \mathrm{MPa}$ in $\mathrm{BM}$ of pipes A and from 620 to $495 \mathrm{MPa}$ in pipes $\mathrm{B}$. In this case, BM demonstrates the highest intensity and the longest strain-hardening time at the uniform stage in the weld joints of pipes of both manufacturers $(K=1665$ and 1473, $n=0.50$ and 0.47 , and $\psi_{\mathrm{u}}=0.28$ and 0.30 for pipes A and $\mathrm{B}$, respectively).

It is of specific interest to estimate the energy of the process. It is known $[6,8]$ that the specific tensile deformation work (tensile toughness $a$ ) is a complex characteristic that is determined by a set of "simpler" mechanical properties of a material, namely, strength $\left(\sigma_{0.2}, \sigma_{u}\right)$ and plastic $\left(\delta_{\mathrm{u}}, \delta, \psi\right)$ properties and is more sensitive to changes in the structural state of the material than these simple properties. It is seen from Table 3 that the specific energy of the uniform stage of plastic deformation is extremely low and depends slightly on the structural change in the welded-joint zones of pipes of both manufacturers $\left(a_{\mathrm{u}}=0.03-0.05 \mathrm{~J} / \mathrm{mm}^{3}\right)$. The main factor controlling the plastic deformation energy at the uniform stage is the fraction of ferrite in a ferrite-bainitemartensite mixture [9].
Structure-sensitive characteristics are the parameters of strain hardening at the concentrated stage of deformation (Table 3). At this stage, plastic deformation in necking to complete fracture of a specimen is accompanied by the growth of a mode I crack, and a ductile cup-shaped relief forms on the fracture surface of a cylindrical specimen. The specific feature of the relief on macroscopic scale is the existence of the following two regions $[6,8]$ : the central region, whose plane is perpendicular to the external tensile force, and the periphery region, whose plane is at an angle of $\sim 45^{\circ}$ to the external tensile force.

As is seen from Tables 2 and 3, the metal of all zones of the welded joint of pipe A has higher characteristics of strain hardening and fracture than those of pipe B. The highest fracture strength $S_{\mathrm{f}}$ is observed in the HAZs of both pipes A (by $600 \mathrm{MPa}$ higher than for the central weld metal and by $110 \mathrm{MPa}$ higher than that of the base metal) and pipes B (by $160 \mathrm{MPa}$ higher than for the central weld metal and by $50 \mathrm{MPa}$ higher than that of the base metal). A similar relation also takes place for the strain hardening intensity $S_{\mathrm{f}} / S_{\mathrm{u}}$, ductility $\psi_{\mathrm{f}}$, tensile toughness $a_{\mathrm{c}}$, and impact toughness $K C \mathrm{~V}$, which are maximal in HAZ of the pipe A welded joint: $S_{\mathrm{f}} / S_{\mathrm{u}}=$ $3.10, \psi_{\mathrm{f}}=1.70, a_{\mathrm{c}}=0.58 \mathrm{~J} / \mathrm{mm}^{2}$, and $K C \mathrm{~V}=304 \mathrm{~J} / \mathrm{cm}^{2}$.

Figure 7 shows the correlation parameters of the fracture energy $(a, K C \mathrm{~V})$ and true stresses $\left(S_{\mathrm{t}}, S_{\mathrm{u}}, S_{\mathrm{f}}\right)$ of the welded joints of the pipes under study. It is seen that stress $S_{\mathrm{t}}$, which characterizes the resistance of a metal to small plastic deformations, is not functionally related to tensile toughness $a$ and impact toughness $K C \mathrm{~V}$, as $S_{\mathrm{u}}$ (Figs. 7a, 7b): at certain stresses, parameters $a$ and $K C \mathrm{~V}$ vary over wide limits. This seems to be related to the fact that the main contribution to the toughness parameters is made by the high degrees of deformations at the concentrated stage. This assumption is supported by good 
Table 3. Energy parameters of the zones in a welded joint

\begin{tabular}{|c|c|c|c|c|c|c|c|}
\hline \multirow{3}{*}{ Specimen } & \multirow{3}{*}{$a_{\mathrm{f}}, \mathrm{J} / \mathrm{mm}^{3}$} & \multirow{3}{*}{$\begin{array}{l}\text { View of the } \\
\text { fracture surface } \\
\text { in the neck }\end{array}$} & \multicolumn{4}{|c|}{ Neck sizes* } & \multirow{3}{*}{$K C \mathrm{~V}, \mathrm{~J} / \mathrm{cm}^{2}$} \\
\hline & & & $d^{\mathrm{h}}$ & $d^{v}$ & $d^{\mathrm{h}} / d^{v}$ & $F, \mathrm{~mm}^{2}$ & \\
\hline & & & \multicolumn{2}{|c|}{$\mathrm{mm}$} & & & \\
\hline \multicolumn{8}{|c|}{ Manufacturer A } \\
\hline $\mathrm{CW}$ & 0.32 & & 5.3 & 5.3 & 1.00 & 22.1 & 174 \\
\hline HAZ & 0.58 & & 5.9 & 3.0 & 1.97 & 13.9 & 304 \\
\hline $\mathrm{BM}$ & 0.54 & & 6.1 & 3.1 & 1.97 & 14.8 & 300 \\
\hline \multicolumn{8}{|c|}{ Manufacturer B } \\
\hline $\mathrm{CW}$ & 0.25 & & 5.8 & 5.8 & 1.00 & 26.4 & 148 \\
\hline HAZ & 0.33 & & 6.8 & 3.9 & 1.74 & 20.8 & 267 \\
\hline BM & 0.36 & & 6.7 & 4.0 & 1.67 & 21.0 & 225 \\
\hline
\end{tabular}

$* d^{\mathrm{h}}$ and $d^{\mathrm{v}}$ are the results of measurements in the horizontal and vertical directions, respectively.

correlation of characteristics $a, K C \mathrm{~V}$, and $S_{\mathrm{f}}$ of the welded joints of pipes of both manufacturers.

The existence of correlations $a-S_{\mathrm{f}}, K C \mathrm{~V}-S_{\mathrm{f}}$ predetermines the existence of correlation $K C \mathrm{~V}-a$ (Fig. 7c). Both characteristics $(K C \mathrm{~V}, a)$ have almost a similar physical meaning, since they describe the work of plastic deformation and fracture of a specimen under conditions of the formation of a three-axial stress state at the final stage of plastic flow preceding fracture. The consideration of correlation $K C \mathrm{~V}-a_{\mathrm{u}}$ would be more objective; however, since $a_{\mathrm{u}}$ is an order of magnitude smaller than $a_{\mathrm{c}}$ and weakly depends on the place of cutting a specimen and the pipe metal composition, the consideration of $a_{\mathrm{u}}$ is not substantial.

Of course, the differences in the method and rate of loading of specimens markedly influence the absolute values of these characteristics, but the existence of a correlation between them indicates that changes of the 

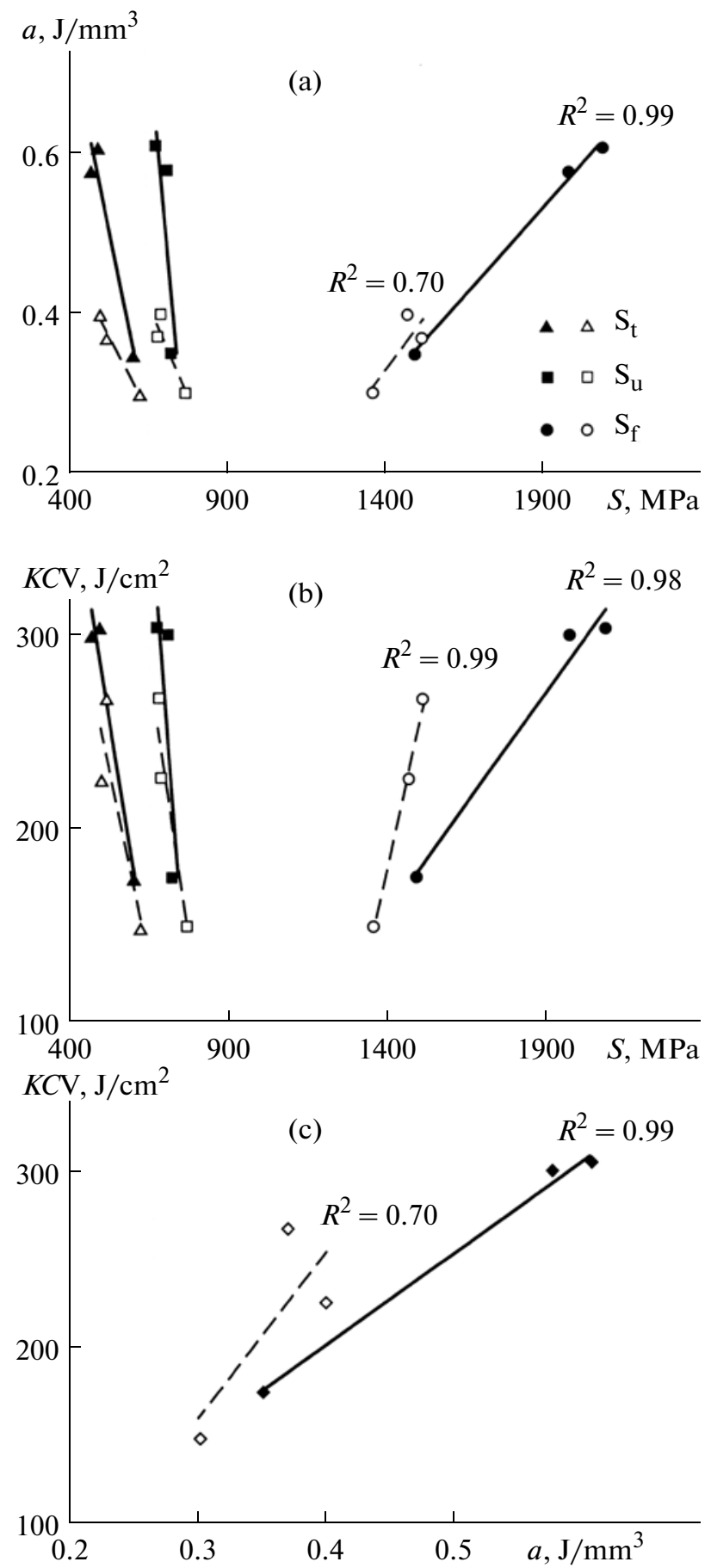

Fig. 7. Correlation fields of the energy parameters of fracture $(a, K C \mathrm{~V})$ with true stresses $S_{\mathrm{t}}, S_{\mathrm{u}}, S_{\mathrm{f}}$ of welded joints of pipes A (solid points) and B (open points).

structural state of steels influence the characteristics in one direction and at the same rate. This can be considered as the principle of similitude and allows us to extend the conclusions made in laboratory tests of specimens to the behavior pf parts (pipes, welded joints) during operation.
The revealed features of the strain hardening of the steels under study affected the characteristics of cup and cone fracture of the specimens subjected to tensile tests (see Table 3). In particular, the neck at the site of fracture of WCZ has a rounded equiaxial shape, and the fracture area induced by a mode I crack in the pipe A weld is smaller than in the pipe B weld.

The relation between the type of fracture surface (cup and cone fracture relief) with the change in the energy of plastic deformation at the stage of concentrated deformation is supported by the tensile toughness $\left(a_{\mathrm{c}}=0.31\right.$ and $0.25 \mathrm{~J} / \mathrm{mm}^{3}$ for the pipe A and B welds, respectively) and the impact toughness $(K C \mathrm{~V}=174$ and $148 \mathrm{~J} / \mathrm{cm}^{2}$, respectively). A similar picture is observed in BM.

At the center of the neck of the specimens cut from HAZ, where the welded joint of pipes of manufacturer A exhibits the largest reserve of toughness, a splitting forms; its appearance is typical of steels after controlled rolling $[10,11]$.

\section{CONCLUSIONS}

(1) Metallographic study of the structure of the base metal, the weld region, and the heat-affected zone in the welded joints of large-diameter pipes of strength class K60 produced by two manufacturers showed that it consists a mixture of ferrite (up to 70\%) and bainite (martensite) of various dispersity and morphology.

(2) The dendrite structure of the welded-joint metal provides the highest strength properties $\left(\sigma_{0.2}=600\right.$ and $620 \mathrm{MPa}, \sigma_{\mathrm{u}}=655$ and $680 \mathrm{MPa}$, for pipes A and B, respectively) at the lowest viscoplastic characteristics $\left(\delta=30-31 \%, \psi=65-70 \%, K C \mathrm{~V}=150-170 \mathrm{~J} / \mathrm{cm}^{2}\right)$ as compared to those of the base metal and the heataffected zone metal, which are almost the same $\left(\sigma_{0.2}=\right.$ $465-515 \mathrm{MPa}, \sigma_{\mathrm{u}}=600-635 \mathrm{MPa},(\delta=32-35 \%, \psi=$ $\left.71-81 \%, K C \mathrm{~V}=225-304 \mathrm{~J} / \mathrm{cm}^{2}\right)$.

(3) It is established that the specific work of deformation (tensile toughness) found from the true stressstrain diagrams of the specimens cut from certain zones of the welded joints of pipes of different manufacturers correlates with true fracture strength $S_{\mathrm{f}}$ and impact toughness $K C \mathrm{~V}$.

(4) The absence of a correlation between the true yield strength, the true ultimate tensile strength, and the fracture toughness or impact toughness allows the conclusion that the work of plastic deformation at the stage of concentrated deformation makes the main contribution to the cracking resistance of the high-toughness steels under study.

(5) The strength and viscoplastic properties of the metal of all regions in the welded joints of pipes of both manufacturers significantly exceed the normative requirements for the welded joints of pipes of strength class K60. At the same time, the toughness characteristics in the weld region are lower than those in the other zones of the welded joint and the base metal, and its hardness and strength are maximal. 


\section{REFERENCES}

1. Yu. D. Morozov, M. Yu. Matrosov, S. Yu. Nastich, and A. B. Arabei, "New-generation high-strength pipe steels with a ferrite-bainite structure," Metallurg, No. 8, 3942 (2008).

2. A. B. Arabei, I. Yu. Pyshmintsev, M. A. Stremel', et al., "The resistance of steels of strength class X80 to the propagation of tough cracks in main gas pipelines," Izv. Vyssh. Uchebn. Zaved., Chern. Metall., No. 9, 3-8 (2009).

3. S. Liu, "Critical concerns of welding high strength steel pipelines X-80 and beyond," Gas and Oil Journal, No. 4, $10-15$ (2009).

4. A. J. DeArdo, "Weldability of linepipe steels," in Proceedings of International Conference Pipes-2007, Chelyabinsk (RosNITI, Chelyabinsk, 2007), pp. 10-15.

5. M. A. Stremel', The Strength of Alloys. II: Deformation (MISiS, Moscow, 1997).

6. V. S. Zolotorevskii, Mechanical Properties of Metals (Metallurgiya, Moscow, 1998).
7. V. M. Farber, "Peculiarities of metal hardening on a fluidity plateau," Metalloved. Term. Obrab. Met., No. 3, 42-44 (2007).

8. W. F. Hosford, Mechanical Behavior of Materials (Cambridge Univ. Press, Cambridge, 2005).

9. V. P. Shveikin, V. A. Khotinov, and V. M. Farber, "Microstructure and the phase composition of low-carbon steels after heating to temperatures of the intercritical range,” Izv. Vyssh. Uchebn. Zaved., Chern. Metall., No. 6, 39-43 (2008).

10. I. Yu. Pyshmintsev, D. A. Pumpyanskii, and V. M. Farber, "The plasticity of steel and its characteristics," Metalloved. Term. Obrab. Met., No. 11, 20-27 (2007).

11. V. V. Orlov, A. V. Il'in, E. I. Khlusova, et al., "Effect of the structural heterogeneity on the mechanical properties of pipe steels of strength class X70-X100," in Proceedings of International Conference Pipes-2010, Chelyabinsk (RosNITI, Chelyabinsk, 2010), pp. 77-90.

Translated by Yu. Ryzhkov 